\title{
Rapid label-free identification of mixed bacterial infections by surface plasmon resonance
}

\author{
Jue Wang ${ }^{1 \dagger}$, Yang Luo ${ }^{1 \dagger}$, Bo Zhang ${ }^{1}$, Ming Chen², Junfu Huang ${ }^{1}$, Kejun Zhang ${ }^{2}$, Weiyin Gao ${ }^{1}$, Weiling Fu ${ }^{1 *}$, \\ Tianlun Jiang ${ }^{3}$ and Pu Liao ${ }^{4}$
}

\begin{abstract}
Background: Early detection of mixed aerobic-anaerobic infection has been a challenge in clinical practice due to the phenotypic changes in complex environments. Surface plasmon resonance (SPR) biosensor is widely used to detect DNA-DNA interaction and offers a sensitive and label-free approach in DNA research.

Methods: In this study, we developed a single-stranded DNA (ssDNA) amplification technique and modified the traditional SPR detection system for rapid and simultaneous detection of mixed infections of four pathogenic microorganisms (Pseudomonas aeruginosa, Staphylococcus aureus, Clostridium tetani and Clostridium perfringens).

Results: We constructed the circulation detection well to increase the sensitivity and the tandem probe arrays to reduce the non-specific hybridization. The use of 165 rDNA universal primers ensured the amplification of four target nucleic acid sequences simultaneously, and further electrophoresis and sequencing confirmed the high efficiency of this amplification method. No significant signals were detected during the single-base mismatch or non-specific probe hybridization $(P<0.05)$. The calibration curves of amplification products of four bacteria had good linearity from $0.1 \mathrm{nM}$ to $100 \mathrm{nM}$, with all $R^{2}$ values of $>0.99$. The lowest detection limits were $0.03 \mathrm{nM}$ for $P$. aeruginosa, $0.02 \mathrm{nM}$ for S. aureus, $0.01 \mathrm{nM}$ for $C$. tetani and $0.02 \mathrm{nM}$ for $C$. perfringens. The SPR biosensor had the same detection rate as the traditional culture method $(P<0.05)$. In addition, the quantification of PCR products can be completed within $15 \mathrm{~min}$, and excellent regeneration greatly reduces the cost for detection.
\end{abstract}

Conclusions: Our method can rapidly and accurately identify the mixed aerobic-anaerobic infection, providing a reliable alternative to bacterial culture for rapid bacteria detection.

Keywords: bacterial infection biosensor, mixed infection, surface plasmon resonance

\section{Background}

Anaerobic bacterial infection is one of the major causes of death due to the difficulty to identify the bacteria $[1,2]$. Among deadly bacteria, Clostridium tetani and Clostridium perfringens frequently lead to severe infections during wartime and other catastrophes. Mixed aerobic-anaerobic infections, such as infection by Pseudomonas aeruginosa and Staphylococcus aureus, are frequently undetected and more severe than either single infection [3]. Early and accurate identification of the pathogenic microorganisms in a co-infection is critical

\footnotetext{
* Correspondence: weilingfu@yahoo.com

† Contributed equally

'Department of Laboratory Medicine, Southwest Hospital, the Third Military Medical University, Chong Qing 400038, P.R China
}

Full list of author information is available at the end of the article for optimizing the treatment, improving the prognosis and decreasing the mortality.

Traditionally, the identification of pathogenic microorganisms mainly depends on a combination of bacterial culture, morphology, biochemical presentations, and immunological examination. Although bacterial culture is extremely time-consuming, it has been the gold standard for identifying bacteria for many years. The growth of anaerobic bacteria always requires rigorous culture conditions, and their phenotypic characteristics (e.g., antibiotic sensitivity and biochemical characteristics) are usually unstable and liable to be affected by gene regulation and plasmid loss [4]. Molecular biological techniques have been widely used to diagnose infections due to their accuracy, rapidity, and specificity. Moreover, nucleic acid amplification by polymerase chain reaction

\section{Biomed Central}


(PCR) allows the detection of trace amounts of target molecules $[5,6]$. Fluorescent quantitative PCR cannot simultaneously discriminate bacteria in mixed infections, despite its potential for relatively accurate quantification. Electrophoresis is a simple and fast technique, but only semi-quantitative due to its limited resolution. Moreover, discrimination among amplification products with similar lengths using electrophoresis is difficult [7].

Surface plasmon resonance (SPR) provides a highly sensitive method for the detection of biomolecular interactions in a label-free manner. Numerous studies on biomolecular interactions have been conducted with SPR on surfaces coated with a variety of biomolecules, including DNA, RNA, proteins and peptides [8-11]. In previous studies, we successfully constructed a series of gene biosensors based on the quartz crystal microbalance, which was then used to quantify the urine proteins, tumor markers, hepatitis B virus, and human papilloma virus [12-14].

In the present study, we developed a new method using the multi-channel SPR biosensor to rapidly and accurately discriminate the mixed aerobic-anaerobic infection in clinical practice. In this study, DNA from four pathogenic microorganisms (P. aeruginosa, S. aureus, C. tetani and $C$. perfringens) was extracted and amplified simultaneously using universal primers. Single-stranded amplicons were then hybridized with a thiolic probe immobilized on the surface of a multi-channel SPR biosensor. The results were then quantitatively analyzed using an image analysis software. The sensitivity, specificity and reproducibility of this method were also evaluated.

\section{Materials and Methods \\ Materials and reagents}

Standard bacterial strains (S. aureus ATCC 25923, P. aeruginosa ATCC 27853, C. perfringens ATCC 64711, and C. tetani ATCC 64041) were purchased from the National Institute for the Control of Pharmaceutical and Biological Products, China. Absolute ethanol (analytically pure) was purchased from Chongqing Chemical Reagent Company, China. Lysozyme, proteinase $\mathrm{K}$ and bacterial genomic DNA extraction kits were purchased from Qiagen (Germany). dNTPs (0.5 mM for each), $10 \times$ PCR buffer, $\mathrm{MgCl}_{2}(2.5 \mathrm{mM})$ and Taq polymerase $(5 \mathrm{U} / \mu \mathrm{l})$ were purchased from Promega, USA. SYBR Green was purchased from DBI, USA. The $16 \mathrm{~S}$ rDNA Bacterial Identification PCR Kit was purchased from TaKaRa, Japan.

\section{Main instruments}

The following instruments were used: PCR amplifer (GeneAmp PCR System 2400; Perkin Elmer), UV spectrophotometer (Bio-Rad SmartspecTM3000), ABI Prism 310 Genetic Analyzer (PerkinElmer), high-speed centrifuge (Beckman Microfuge 22R), BIO-CAPT gel imaging system (VILBER LOURMAT, BIO-PKOFIL Company, France), electrical thermostatic water bath tank (SHHW21600-II, Yuejing Medical, China), API biochemical identification system and Model FX-DY-252 electrophoresis apparatus (Fuxing Tech, China).

\section{SPR biosensor}

The SPR biosensor system was modified by our laboratory and composed of an incident light source (polarized light), a sample-loading chamber, a detection well, a temperature control system and a light detector (Figure 1). The sample-loading chamber was designed based on an aspiration mechanism and can suck samples into the detection system through a micro-flow pump. The detection well was designed as a closed, cycle, thin and flat chamber to maximize the contact area in the reaction. A sensor chip $(5 \mathrm{~mm} \times 10 \mathrm{~mm})$ with immobilized specific nucleic acid probes was placed in the middle of the detection well. The four probes specific to $S$. aureus, $P$. aeruginosa, C. perfringens, and C. tetani were arrayed in different zones of the chip surface. The temperature control system was designed based on pulse mechanism and can maintain a predetermined temperature with an accuracy of $\pm 0.1^{\circ} \mathrm{C}$ at $25 \sim 60^{\circ} \mathrm{C}$, allowing most nucleic acid hybridizations. The light source system was made up of an incident light source and a signal detector.

The detection principles are as follows: i) when the sample solution contacts the SPR biosensor, the biological molecules bind specifically to the target molecules in the sample solution to form complexes; ii) these complexes may change the surface structure of the biological molecule monolayer, leading to an SPR angle shift; iii) the angle shift is then detected by an optical recording device; and iv) the concentration of target molecule is determined by comparing the resulting angle shift with that in a calibration curve.

\section{Design of primers and probes}

Universal primers (Table 1) were used for the amplification of ssDNA of $S$. aureus, $P$. aeruginosa, $C$. tetani and C. perfringens. Four pathogenic bacterium-specific probes were also designed using the Primer Premier Software. To verify the specificity of each probe, three additional nucleotide sequences were designed. Each contained a single-base mismatch to the $S$. aureus probe with one at the 5' end, one at the 3' end and one in the middle of the probe (Table 1). All primers and probes were synthesized by Shanghai BioAsia Company, and the probes labeled with a hydrosulfide at the 5 ' end.

\section{Bacterial culture and identification}

Four lyophilized bacterial strains were cultured in $\mathrm{TH}$ broth with sulfate acetate at $37^{\circ} \mathrm{C}$ for $24 \mathrm{~h}$ and then on blood agar plates at $37^{\circ} \mathrm{C}$ for 24 h. C. tetani and $C$. 


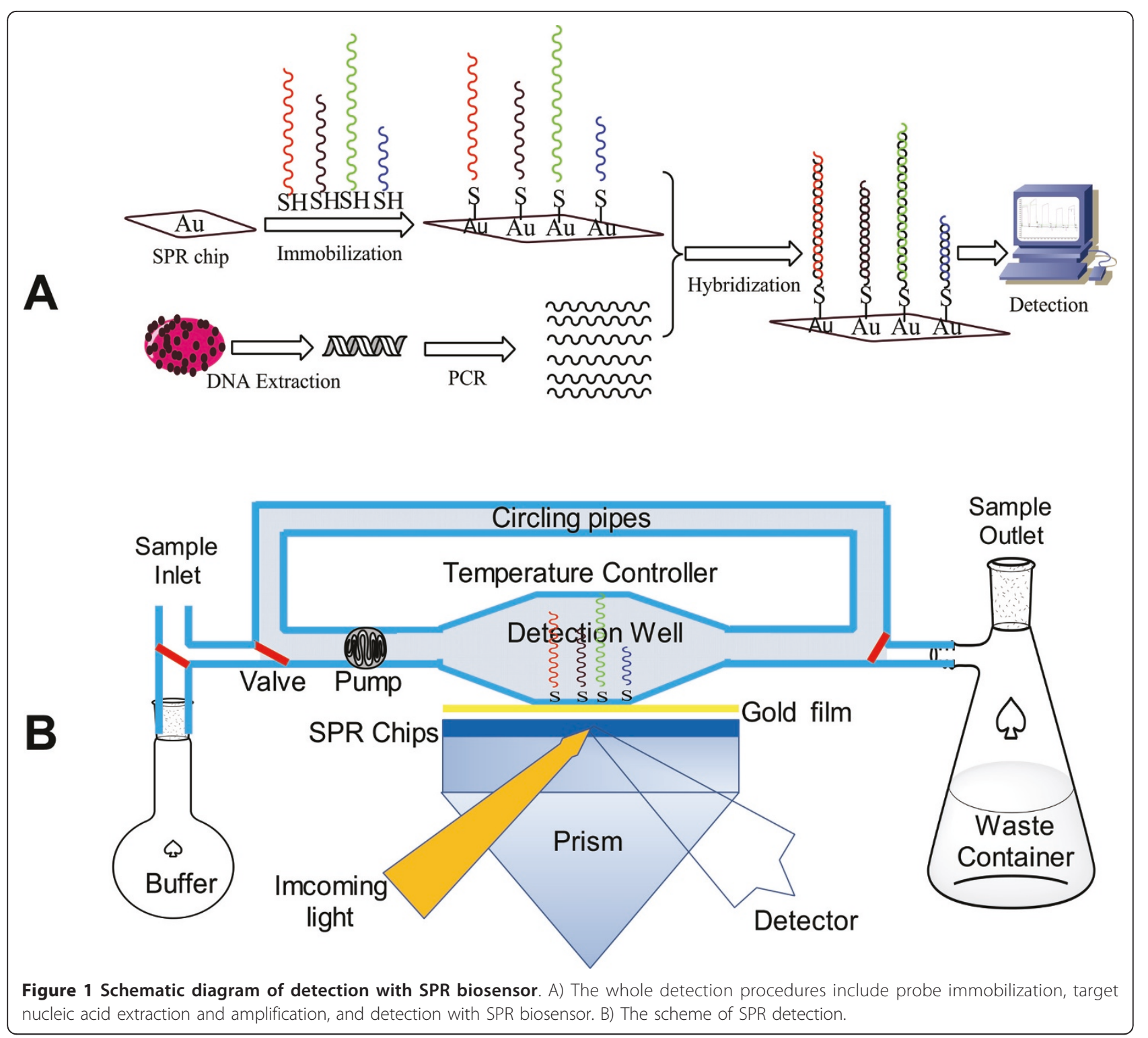

perfringens were inoculated onto the anaerobic blood agar plates and cultured in an anaerobic incubator at $37^{\circ} \mathrm{C}$ for $48 \mathrm{~h}$. The colonies were selected for microscopic examination and biochemical identification using the API biochemical identification system. API Staph (BioMerieux, USA) was used for identification of $S$ aureus and API 20 A (BioMerieux, USA) for identification of $P$. aeruginosa, $C$. tetani and $C$. perfringens..

Table 1 Nucleotide sequences of ssDNA used in this study

\begin{tabular}{|c|c|c|}
\hline & Primer a & 5'-GTAGGAGTCTGGACCGTGTC-3' \\
\hline \multirow[t]{3}{*}{ PCR Primers } & Primer $b$ & 5'-CGGCGTGCCTAATACATG-3' \\
\hline & Primer c & 5'-cgccccGTAGGAGTCTGGACCGTGTC-3' \\
\hline & S. aureus & 5'-SH-ACAGCAAGACCGTCTTTCACTTTTG-3' \\
\hline \multirow[t]{3}{*}{ Probes } & P. aeruginosus & 5'-SH-CCACTTTCTCCCTCAGGACGTATG-3' \\
\hline & C. tetanus & 5'-SH-GCCCATCTCAAAGCAGATTACTC-3' \\
\hline & C. perfringens & 5'-SH-ATCTCATAGCGGATTGCTCCTITGG-3' \\
\hline Single-base & S. aureus 1 & 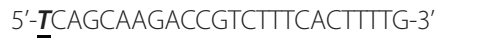 \\
\hline Mismatch sequence & S. aureus 2 & 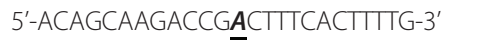 \\
\hline probe & S. aureus 3 & 5'-ACAGCAAGACCGTCTTTCACTITI $\underline{C}-3^{\prime}$ \\
\hline
\end{tabular}




\section{Preparation of bacterial DNA}

Bacteria suspension was prepared at a density of $1 \times 10^{8}$ $\mathrm{cfu} / \mathrm{ml}$ with $0.9 \%$ sterile normal saline. Then, $1 \mathrm{ml}$ of bacterial suspension was centrifuged at $8,000 \mathrm{rpm}$ for 5 $\min$ at $4^{\circ} \mathrm{C}$, and the supernatant was removed. After addition of $10 \mu \mathrm{l}$ of lysozyme $(100 \mathrm{mg} / \mathrm{ml})$, the suspension was incubated at $37^{\circ} \mathrm{C}$ for $100 \mathrm{~min}$, followed by centrifugation at 4,000 $\mathrm{g}$ and removal of supernatant. According to the manufacturer's instructions (FlexiGene DNA Kit, Qiagen, Germany), $400 \mu$ l of the eluent were obtained and stored at $-20^{\circ} \mathrm{C}$ for use.

\section{Amplification of single-stranded DNA and sequencing of four bacterial genes}

The mixture for PCR was as follows: $5 \mu \mathrm{l}$ of $10 \times \mathrm{PCR}$ buffer, $4 \mu \mathrm{l}$ of $10 \mathrm{mmol} / \mathrm{l} \mathrm{dNTP}$ mix; $1 \mu \mathrm{l}$ of $10 \mu \mathrm{mol} / \mathrm{l}$ $16 \mathrm{~s}-\mathrm{a}, 1 \mu \mathrm{l}$ of $10 \mu \mathrm{mol} / \mathrm{l} 16 \mathrm{~s}-\mathrm{b}, 1 \mu \mathrm{l}$ of $10 \mu \mathrm{mol} / \mathrm{l} 16 \mathrm{~s}-\mathrm{c}$, $0.5 \mu \mathrm{l}$ of Tap polymerase, $1 \mu \mathrm{l}$ of template and $36.5 \mu \mathrm{l}$ of dd $\mathrm{H}_{2} \mathrm{O}$. PCR was carried out according to the linearafter-the-exponential (LATE)-PCR protocol with slight modification [15]: pre-denaturation at $94^{\circ} \mathrm{C}$ for $10 \mathrm{~min}$, then 25 cycles of denaturation at $94^{\circ} \mathrm{C}$ for $30 \mathrm{~s}$, annealing at $49^{\circ} \mathrm{C}$ for $40 \mathrm{~s}$ and extension at $72^{\circ} \mathrm{C}$ for $40 \mathrm{~s}$, and 40 cycles of denaturation at $94^{\circ} \mathrm{C}$ for $30 \mathrm{~s}$, annealing at $68^{\circ} \mathrm{C}$ for $40 \mathrm{~s}$, and extension at $72^{\circ} \mathrm{C}$ for $40 \mathrm{~s}$ and a final extension $72^{\circ} \mathrm{C}$ for $4.5 \mathrm{~min}$. The PCR products were subjected to $1 \%$ agarose gel electrophoresis and visualized using SYBR Green. All PCR products were gel-purified and submitted for sequencing.

\section{Immobilization of probes onto the biosensor}

The reaction was carried out at $45^{\circ} \mathrm{C}$ using $\mathrm{HBS}-\mathrm{EP}$ $(\mathrm{pH} 7.4)$ as system buffer. The target probes $(0.20 \mu \mathrm{M})$ were dissolved in HBS-EP ( $\mathrm{pH} 7.4$ ), and $300 \mu \mathrm{L}$ of this solution was transferred into the detection pipe at a speed of $5 \mu \mathrm{L} / \mathrm{min}$. A total of $300 \mu \mathrm{L}$ of HBS-EP ( $\mathrm{pH}$ $7.4)$ containing negative control probe $(0.20 \mu \mathrm{M})$ was transferred into the control pipe at a speed of $5 \mu \mathrm{L} /$ min. After the reaction completed, the chip surface (precoated with probes) was regenerated by washing with $100 \mu \mathrm{L}$ of $0.01 \%$ SDS and $100 \mu \mathrm{L}$ of $5 \mathrm{mM} \mathrm{HCl}$ at a speed of $50 \mu \mathrm{L} / \mathrm{min}$. To equilibrate the chip surface, system buffer was supplemented at a speed of $200 \mu \mathrm{L} / \mathrm{min}$ for $30 \mathrm{~min}$.

\section{Detection of bacteria}

The PCR products were added into the SPR monitoring system, and the temperature was adjusted to $45^{\circ} \mathrm{C}$. Any change in the refraction angle due to the nucleic acid hybridization was recorded in a real time manner and then converted into electrical signals which were then used to determine the concentration using the system software.

\section{Calibration}

DNA was extracted from each standardized bacterial strain $(50 \mathrm{cfu} / \mathrm{ml})$ and subjected to amplification by PCR according to procedures described above. The products were diluted to $100,50,10,5$ and $1 \mathrm{nM}$ and then hybridized with the specific probes on the SPR biosensor. Finally, standard curves were delineated.

\section{Determination of sensitivity}

The buffer without bacteria was added to the detection well as a blank. The blank was tested 10 times, and the average and three standard deviations were used as the baseline detection limit.

\section{Determination of probe specificity}

After each $S$. aureus probe $(1 \mu \mathrm{M})$ and the single-base mismatch sequence probes ( $S$. aureus 1, 2 and 3) were immobilized on the surface of SPR biosensor, the PCR product $(100 \mathrm{nM})$ of $S$. aureus was added to the detection well. The changes in the refraction angle due to nonspecific binding were recorded. Then, the probes specific for four bacteria were immobilized on the SPR chips. The product of a combined four-bacterium pure culture was added to the detection well, and the changes in the refraction angle due to nonspecific binding were recorded.

\section{Regeneration performance testing}

After each detection, $100 \mu \mathrm{L}$ of $0.01 \%$ SDS and $100 \mu \mathrm{L}$ of $5 \mathrm{mM} \mathrm{HCl}$ were added to the detection well to dissociate the bound target DNA. Then, the well was washed thrice with PBS. The same sample was re-added to the well, and the hybridization signal recorded. The concentration of samples was $50 \mathrm{nM}$ and this procedure was repeated 200 times to determine the regeneration performance.

\section{Clinical sample detection}

DNA was extracted from 365 tissues infected with $S$. aureus, $P$. aeruginosa, C. tetani and C. perfringens (as confirmed by bacterial culture). All experiments were performed with the approval of the Ethics Committee of Third Military Medical University. After amplification by PCR, the resulting products were added to the SPR detection well as described above. Then, the positive and negative detection rates were determined.

\section{Data analysis}

All experiments were performed at least three times and statistical analysis was performed with SPSS version 15.0 (Statistical Package for the Social Sciences, SPSS Inc, Chicago, Illinois). The changes in SPR angle were presented as the means \pm standard deviation (SD). 
One-way analysis of variance (ANOVA) was used to compare the differences among different probe groups. McNemar's test was employed to compare the consistency between the SPR detection and the traditional culture method. A value of $\mathrm{P}<0.05$ was considered statistically significant.

\section{Results}

\section{Bacterial culture and isolation}

Colonies obtained by bacterial revival, isolation and culture were identified using the API biochemical identification system and used as the target bacterial strains (data not shown).

\section{Identification of PCR products}

Although the marker was understained (lane $M$ ), the PCR products in lanes 1 to 8 were bright (Figure 2). In addition, the $P$. aeruginosa (lane 9) and $S$. aureus (lane 10) plasmids had similar brightness and position as the PCR products, indicating that most of PCR products were ssDNA. Sequencing confirmed that the four specific sequences after PCR amplification were the expected sequences of $S$. aureus, $P$. aeruginosa, C. tetani and $C$. perfringens (data not shown).

\section{Specificity of the detection with SPR biosensor}

Two experiments were designed to validate the specificity of the detection with SPR biosensor. In the presence of a complementary sequence with a single-base

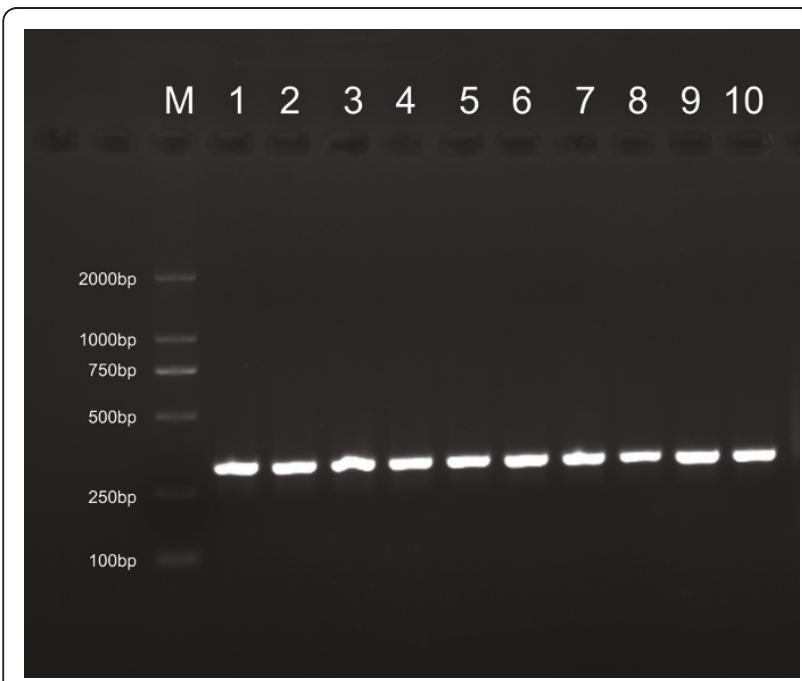

Figure 2 Electrophoresis of single-stranded PCR products. All the nucleic acids were stained by SYBR Green II. The marker was lightly stained, whereas the optical density of ssDNA band was relatively high. Lane 1 and 2: C. perfringens, lane 3 and 4: C. tetani, lane 5 and 6: P. aeruginosa, and lane 7 and 8: S. aureus in duplicates. Plasmid of $P$. aeruginosa (lane 9), and S. aureus (lane 10) were used to identify the length of ssDNA. mismatch, the change in the SPR angle was small (Figure 3A), and there was no significant difference among the SPR angle shifts for the three different probes with mismatch in different sites. Cross-reaction between the target and the non-specific complementary probes was very low (Figure 3B).

\section{Calibration and baseline detection limit}

Serial dilutions of the PCR products $(100,50,10,5,1$, 0.5 and $0.1 \mathrm{nM}$ ) were measured to calibrate the detection with SPR biosensor. All the correlation coefficients of the standard curves were $>0.99$, indicating favorable linearity (Figure 4A). The detection limits were $0.02 \mathrm{nM}$ for $S$. aureus, $0.03 \mathrm{nM}$ for $P$. aeruginosa, $0.03 \mathrm{nM}$ for $C$. perfringens, and $0.01 \mathrm{nM}$ for C. tetani.

\section{Detection of clinical samples}

Among 365 samples, all were found to be infected by one or more of these four bacteria demonstrated by a culture-based method. The sensitivity and specificity of the detection with SPR biosensor were 92.86\% and 95.65\%, respectively, for $P$. aeruginosa, $98.33 \%$ and $100 \%$, respectively, for S. aureus, $96.67 \%$ and $97.14 \%$, respectively, for C. perfringens and $91.67 \%$ and $96.23 \%$, respectively, for $C$. tetani (Table 2 ). These findings indicate good consistency between the detection with SPR biosensor and the traditional culture method.

\section{Regeneration performance}

Results demonstrated that the detection with SPR biosensor had good regeneration performance. Over the first 100 regeneration tests, the SPR angle decreased < $20 \%$. After 100 regeneration tests, however, the hybridization efficiency decreased rapidly. After 200 regeneration tests, the efficiency was $<50 \%$. These findings indicate that a well-immobilized SPR biosensor chip can be regenerated more than 100 times (Figure 4B).

\section{Discussion}

Discriminating a mixed bacterial infection by traditional culture- and biochemical character-based methods is a challenge in clinical practice because the bacteria in the mixed infection are apt to produce atypical phenotypes. Molecular biological methods such as SPR biosensing can detect the specific nucleic acid of bacterial genomes and thus avoid the difficulties associated with phenotypic changes. Currently, the $16 \mathrm{~S}$ rDNA, a gene encoding the small ribosomal RNA subunit, is widely used for the identification of bacteria in the mixed infection because its sequence contains conserved regions common to all bacteria and divergent regions unique to each species. Although amplification using universal primers is critical for the multiple target analysis, it usually leads to nonspecific PCR products [16]. In this study, the formation 


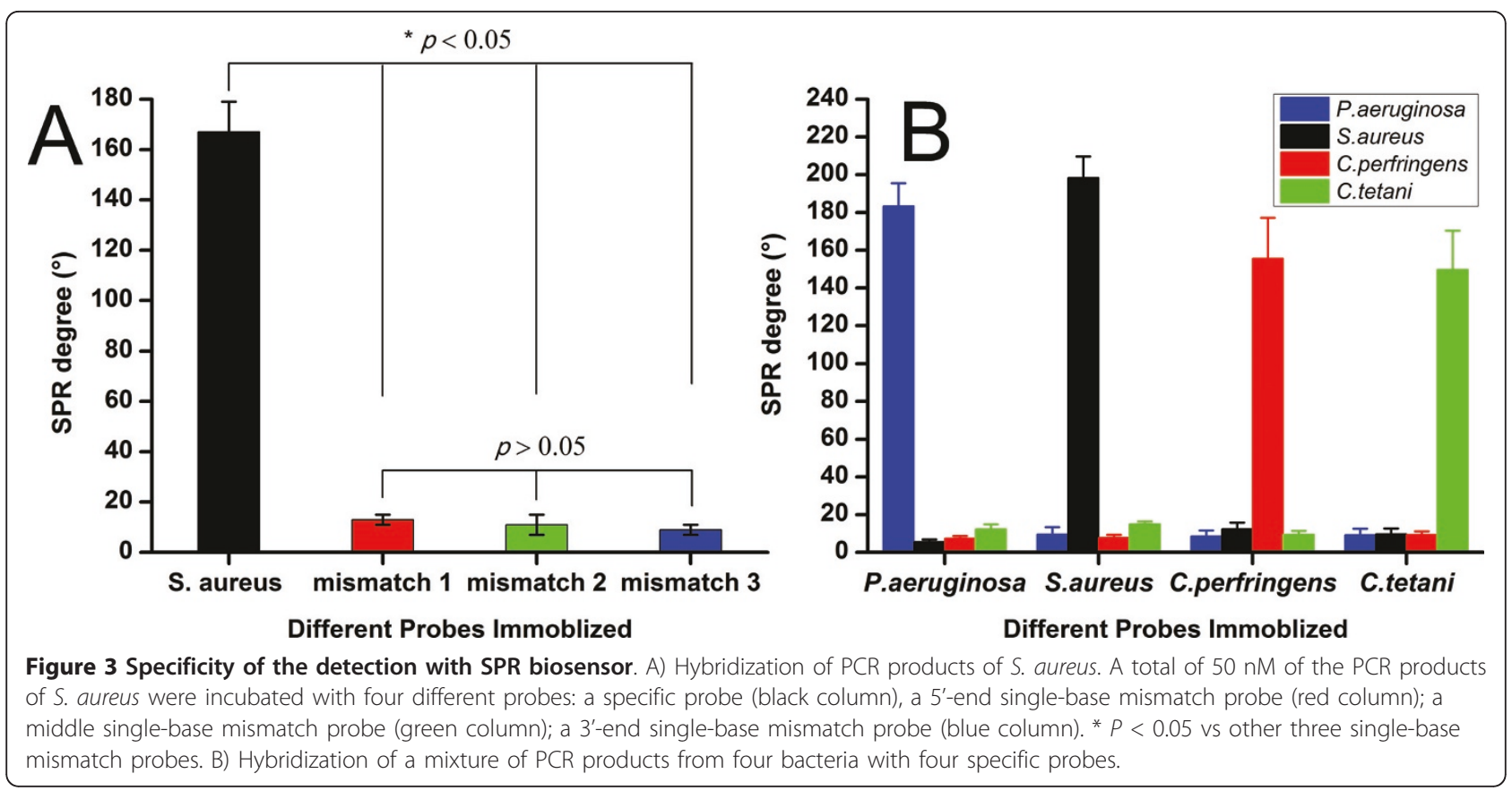

of nonspecific PCR products was avoided by optimizing the PCR reaction conditions. Sequencing showed that the universal primers successfully amplified the target DNA from all four bacteria in the analyte mixture.

Amplification of single-stranded DNA is a notable characteristic of this method. Conventional PCR usually consists of 35 cycles of reaction and yields doublestranded products that require being unwound at hightemperature before they can be detected through hybridization. This may correspondingly increases the number of steps and the complexity of device. In addition, it often leads to incomplete unwinding or mismatches between some bases, which is inconvenient for the development of a specific and sensitive assay. Therefore, single-stranded DNA was used for hybridization. According to the LATE-PCR protocol and previously reported [17], we designed three universal primers to ensure the formation of ssDNA. Electrophoresis showed that most of the products were ssDNA. Sequencing confirmed that the amplified ssDNA was the target sequence, indicating that this method accurately amplified ssDNA.

SPR systems are sensitive to the changes in the thickness or refractive index of the gold film coated at the interface between the chip surface and an ambient medium. Hybridization between a probe immobilized on the chip surface and its target may cause the conformational changes in the surface of the gold electrodes leading to corresponding changes in the refractive index. SPR has several advantages in clinical practice. Firstly, it has the capability of realtime monitoring, which is a crucial characteristic of biosensors and also reduces the detection time. Once the refractive index changes when the DNA-DNA reactions between the probes and target sequences occur, hybridization can be detected in a real-time manner by continuously monitoring the refractive index of the gold film coated on the sensor (Figure 5). Secondly, this method is a label-free technique. Thus, the problems associated with fluorescence quenching or radioactive exposure are avoided. This technique also improves the accuracy of detection and reduce the detection time [18].

Rapidity is the most prominent advantage of this method. This detection can be finished within $15 \mathrm{~min}$, and the whole detection process, including DNA extraction, denaturation, PCR amplification and real-time detection, can be done within $3 \sim 4 \mathrm{~h}$. In addition, the conventional DNA extraction and denaturation were employed into this method because both techniques are mature and commercially available.

To increase the accuracy of detection, four probes were arranged in a tandem model, and samples containing mixed bacteria passed through the detection well to hybridize with probes specific for $S$. aureus, $P$. aeruginosa, C. tetani and C. perfringens. At the optimal temperature, specific nucleic acid probes hybridized with their specific target sequences, which gradually decreased the amount of target molecules in the sample. To increase the accuracy of detecting low-concentration 


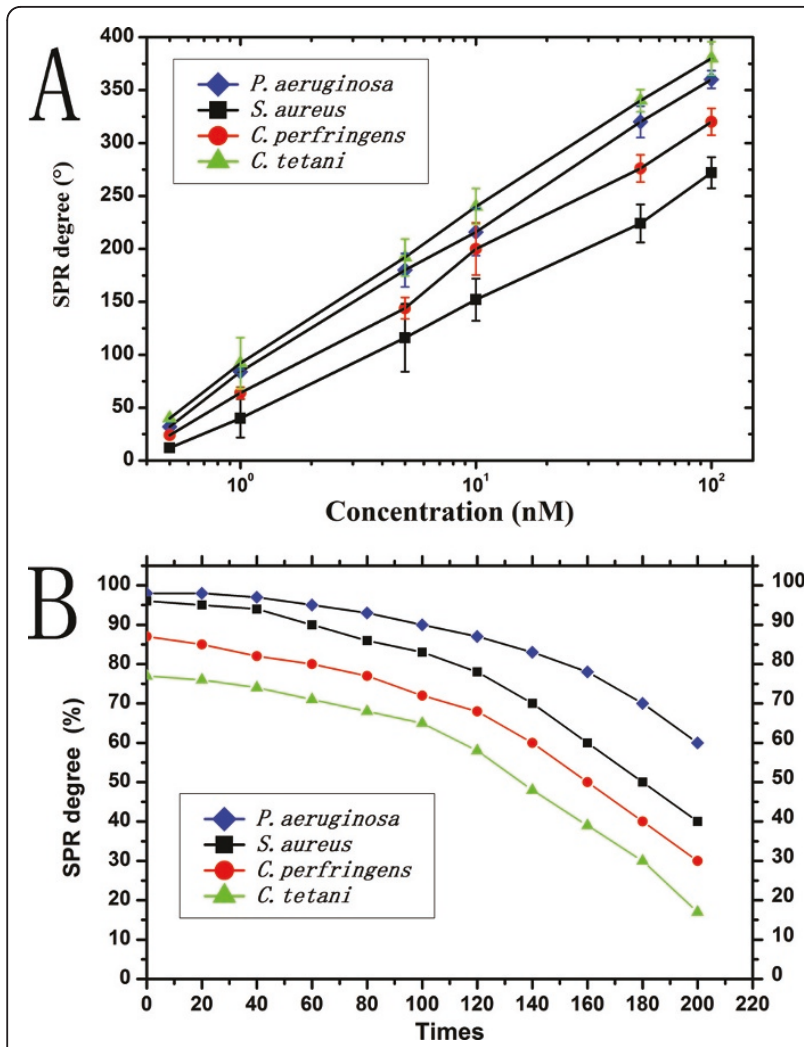

Figure 4 A) Calibration curves of each bacterium at the concentrations of $0.1 \mathrm{nM}, 0.5 \mathrm{nM}, 1 \mathrm{nM}, 5 \mathrm{nM}, 10 \mathrm{nM}, 50 \mathrm{nM}$ and $100 \mathrm{nM}$. All curves fitted well logarithmically, with the formulas as follows: $y=0.153 \times \ln (x)+0.197$, with $R^{2}=0.9991$ for $P$. aeruginosa (blue diamonds); $y=0.121 \times \ln (x)+0.103$, with $R^{2}=$ 0.9974 for S. aureus (black squares); $y=0.139 \times \ln (x)+0.157$, with $R^{2}=0.9974$ for C. perfringens (red circles); and $y=0.160 \times \ln (x)+$ 0.222 , with $R^{2}=0.9994$ for $C$. tetani (green triangles). B) Regeneration of the detection with SPR biosensors. Data were expressed as the percentage of maximal SPR degree angle. All the SPR angles decreased with an increase of regeneration. All the SPR angles decreased slightly during the first 100 tests but were still higher than $80 \%$, whereas they dropped rapidly in the another round of 100 tests analytes, the samples repeatedly passed through the tandemly arranged probes in a circulating detection well. The reaction time could be controlled by adjusting the flow velocity, and the optimal velocity was determined to be $3 \sim 5 \mathrm{~mm} / \mathrm{s}$. The advantages of a tandem probe array include the high accuracy, the low interference between probes, and the possibility of simultaneous detection of more target molecules by simply increasing the types of tandem probes.

The sensitivity and specificity are crucial determinants of sensor performance, which were also investigated in this study. The results demonstrated that this method had a sensitivity equivalent to conventional culture method. The analysis of specificity demonstrated that hybridization did not occur in the probes containing single-base mismatches. The location of the mismatch site within the probe did not affect the results, which was partially consistent with previously reported $[19,20]$. This may be attributed to that the SPR angle shifts induced by all three types of hybridization were too low to be discriminated by the biosensor. There were no obvious cross-reactions between the four bacteria (Figure 3). These findings demonstrate the high efficiency of SPR biosensor. Testing clinical samples indicated that this method and the traditional culture method correlated significantly in terms of the detection rate. Our method, however, can shorten the detection time substantially from one week in traditional method to $2 \sim 3 \mathrm{~h}$.

Although this biosensor successfully identified different types of microorganisms in most clinical samples, it is currently unable to quantify the bacterial load in vivo, which is important for clinical assessment, medication and prognosis. Because this method involves PCR amplification, quantitative analysis relies on the quantity of the template during the pretreatment, and multiple factors may affect the outcome of this analysis. A standardized sample processing procedure is therefore required to accurately quantify these pathogenic bacteria.

Table 2 Comparison of the SPR biosensor and bacterial culture in the detection of four bacteria

\begin{tabular}{|c|c|c|c|c|c|c|c|c|c|}
\hline \multirow{3}{*}{ Culture method } & \multicolumn{8}{|c|}{ SPR biosensor method } & \multirow{3}{*}{ Total } \\
\hline & \multicolumn{2}{|c|}{ P. aeruginosa } & \multicolumn{2}{|c|}{ S.aureus } & \multicolumn{2}{|c|}{ C.perfringens } & \multicolumn{2}{|c|}{ C.tetani } & \\
\hline & $P^{*}$ & $\mathrm{~N}^{* *}$ & $P$ & $\mathrm{~N}$ & $P$ & $\mathrm{~N}$ & $P$ & $\mathrm{~N}$ & \\
\hline$P$ & 238 & 3 & 249 & 2 & 228 & 1 & 110 & 2 & \\
\hline N & 4 & 120 & 1 & 113 & 2 & 134 & 1 & 252 & \\
\hline Total & 242 & 123 & 250 & 115 & 230 & 135 & 111 & 254 & 365 \\
\hline
\end{tabular}

* P: positive, and ${ }^{* *} \mathrm{~N}$ : negative. No significant difference in the detection of four bacteria in mixed infection was found between bacterial culture and SPR biosensor $(P>0.05)$. The differences and $95 \% \mathrm{Cl}$ were $3.08 \%$ and $-3.76 \% \sim 6.08 \%$, respectively, for $P$. aeruginosa; $1.54 \%$ and $-1.46 \% \sim 1.45 \%$, respectively, for $S$. aureus; $0 \%$ and $-3 \% \sim 3 \%$, respectively, for C. perfringens and $1.54 \%$ and $-3.74 \% \sim 4.54 \%$, respectively, for C.tetani. 


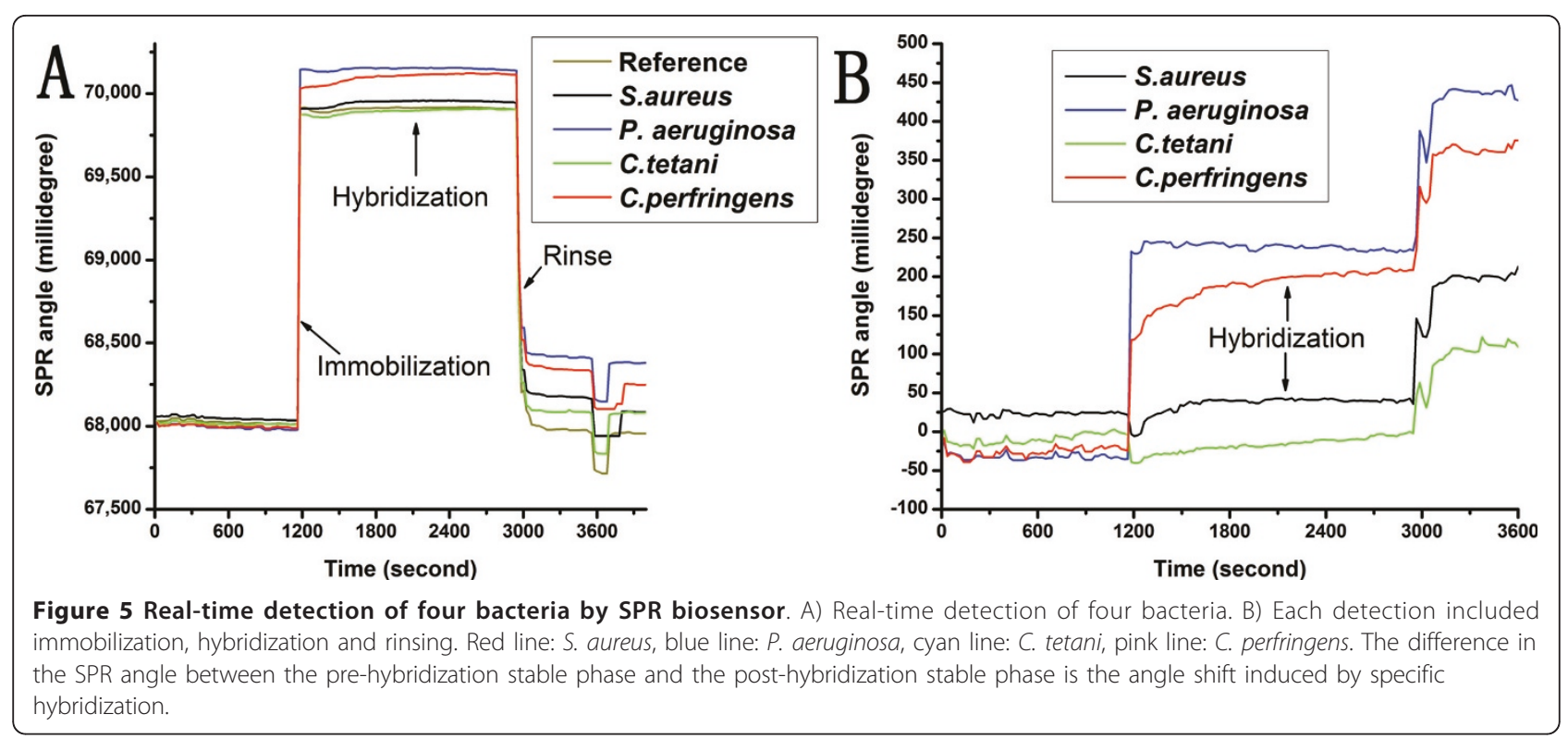

\section{Conclusions}

Our method allows for the simultaneous, real-time discrimination of S. aureus, P. aeruginosa, C. tetani and $C$. perfringens in mixed bacterial infections. Moreover, this method has a specificity equivalent to bacterial culturebased methods and allows for the semi-quantitative assessment of multiple bacteria, which is helpful for the clinical diagnosis and follow-up treatment. This method may become a highly promising technique for the microorganism analysis.

\section{List of abbreviations}

SPR: Surface plasmon resonance.

\begin{abstract}
Acknowledgements
This study was supported in part by grants from the National Natural Science Foundation of China (30900348, 30927002), Key Science and Technology Project of People's Liberation Army (08G089, 08JKS01), Foundation for Science \& Technology Research Project of Chongqing (CSTC,2010AA5042), and special foundation for transformation of Science \& Technology Achievements from the Third Military Medical University, China (2010XZH08, SWH2008008). We appreciate Qianglin Duan from Tongji Hospital for critical reading of the manuscript.
\end{abstract}

\section{Author details}

'Department of Laboratory Medicine, Southwest Hospital, the Third Military Medical University, Chong Qing 400038, P.R China. ²Department of Laboratory Medicine, Daping Hospital, the Third Military Medical University, Chong Qing 400040, P.R China. ${ }^{3}$ Department of Transfusion Medicine, Southwest Hospital, the Third Military Medical University, Chong Qing 400038, P.R China. ${ }^{4}$ Chongqing Center of Clinical Laboratory, Chong Qing 400014, P.R China.

\section{Authors' contributions}

JW and YL have made substantial contributions to conception and design, data acquisition, analysis and data interpretation and are involved in drafting and revising the manuscript. WF has made substantial contributions to conception and design.

$\mathrm{BZ}, \mathrm{MC}, \mathrm{TJ}, \mathrm{PL}, \mathrm{JH}, \mathrm{KZ}$ and $\mathrm{WG}$ have made substantial contributions to data acquisition, analysis and data interpretation. Moreover, each author has taken public responsibility for appropriate portions of the content. All authors read and approved the final manuscript

\section{Competing interests}

The authors declare that they have no competing interests.

Received: 26 February 2011 Accepted: 7 June 2011

Published: 7 June 2011

\section{References}

1. Brook I: Microbiology and management of joint and bone infections due to anaerobic bacteria. J Orthop Sci 2008, 13:160-169.

2. Tunney MM, Field TR, Moriarty TF, Patrick S, Doering G, Muhlebach MS, Wolfgang MC, Boucher R, Gilpin DF, McDowell A, Elborn JS: Detection of anaerobic bacteria in high numbers in sputum from patients with cystic fibrosis. Am J Respir Crit Care Med 2008, 177:995-1001.

3. Lin YC, Tu CY, Chen W, Tsai YL, Chen HJ, Hsu WH, Shih CM: An urgent problem of aerobic gram-negative pathogen infection in complicated parapneumonic effusions or empyemas. Intern Med 2007, 46:1173-1178.

4. Rainey FA, Ward NL, Morgan HW, Toalster R, Stackebrandt E: Phylogenetic analysis of anaerobic thermophilic bacteria: aid for their reclassification. J Bacteriol 1993, 175:4772-4779.

5. Wilson WJ, Strout CL, DeSantis TZ, Stilwell JL, Carrano AV, Andersen GL: Sequence-specific identification of 18 pathogenic microorganisms using microarray technology. Mol Cell Probe 2002, 16:119-127.

6. Tissari P, Zumla A, Tarkka E, Mero S, Savolainen L, Vaara M, Aittakorpi A, Laakso S, Lindfors M, Piiparinen H, Mäki M, Carder C, Huggett J, Gant V: Accurate and rapid identification of bacterial species from positive blood cultures with a DNA-based microarray platform: an observational study. Lancet 2010, 375:224-230.

7. Martin WJ: Rapid and reliable techniques for the laboratory detection of bacterial meningitis. Am J Med 1983, 75:119-123.

8. Nakatani K, Sando S, Saito I: Scanning of guanine-guanine mismatches in DNA by synthetic ligands using surface plasmon resonance. Nat Biotechnol 2001, 19:51-55.

9. Chu LQ, Forch R, Knoll W: Surface-plasmon-enhanced fluorescence spectroscopy for DNA detection using fluorescently labeled PNA as "DNA indicator". Angew Chem Int Edit 2007, 46:4944-4947.

10. Sannomiya T, Hafner C, Voros J: In situ sensing of single binding events by localized surface plasmon resonance. Nano Lett 2008, 8:3450-3455.

11. Scarano S, Mascini M, Turner AP, Minunni M: Surface plasmon resonance imaging for affinity-based biosensors. Biosens Bioelectron 2010, 25:957-966.

12. Luo Y, Chen M, Wen QJ, Zhao M, Zhang B, Li XY, Wang F, Huang Q, Yao CY, Jiang TL, Cai GR, Fu WL: Rapid and simultaneous quantification of 
4 urinary proteins by piezoelectric quartz crystal microbalance immunosensor array. Clin Chem 2006, 52:2273-2280

13. Zhang B, Zhang X, Yan HH, Xu SJ, Tang DH, Fu WL: A novel multi-array immunoassay device for tumor markers based on insert-plug model of piezoelectric immunosensor. Biosensors \& Bioelectronics 2007, 23:19-25.

14. Wang YX, Chen M, Zhang LQ, Ding Y, Luo Y, Xu QH, Shi JF, Cao L, Fu WL: Rapid detection of human papilloma virus using a novel leaky surface acoustic wave peptide nucleic acid biosensor. Biosensors \& Bioelectronics 2009, 24:3455-3460.

15. Pierce KE, Sanchez JA, Rice JE, Wangh L: Linear-After-The-Exponential (LATE)-PCR: primer design criteria for high yields of specific singlestranded DNA and improved real-time detection. Proc Natl Acad Sci USA 2005, 102:8609-8614

16. Baker GC, Cowan DA: $16 \mathrm{~S}$ rDNA primers and the unbiased assessment of thermophile diversity. Biochem Soc Trans 2004, 32:218-221.

17. Sanchez JA, Pierce KE, Rice JE, Wangh LJ: Linear-after-the-exponential (LATE)-PCR: an advanced method of asymmetric PCR and its uses in quantitative real-time analysis. Proc Natl Acad Sci USA 2004, 101:1933-1938

18. Sorger PK: Microfluidics closes in on point-of-care assays. Nat Biotechnol 2008, 26:1345-1346.

19. Garcia T, Revenga-Parra M, Abruna HD, Pariente F, Lorenzo E: Singlemismatch position-sensitive detection of DNA based on a bifunctional ruthenium complex. Anal Chem 2008, 80:77-84.

20. Naiser T, Ehler O, Kayser J, Mai T, Michel W, Ott A: Impact of pointmutations on the hybridization affinity of surface-bound DNA/DNA and RNA/DNA oligonucleotide-duplexes: comparison of single base mismatches and base bulges. BMC Biotechnol 2008, 8:48.

doi:10.1186/1479-5876-9-85

Cite this article as: Wang et al:: Rapid label-free identification of mixed bacterial infections by surface plasmon resonance. Journal of

Translational Medicine 2011 9:85.

\section{Submit your next manuscript to BioMed Central and take full advantage of:}

- Convenient online submission

- Thorough peer review

- No space constraints or color figure charges

- Immediate publication on acceptance

- Inclusion in PubMed, CAS, Scopus and Google Scholar

- Research which is freely available for redistribution

Submit your manuscript at www.biomedcentral.com/submit 